\title{
Semiological bridge between psychiatry and epilepsy
}

\begin{abstract}
Epilepsy is a paroxysmal disturbance of brain function that presents as behavioral phenomena involving four spheres; sensory, motor, autonomic and consciousness. These behavioural disturbances though transient but may be confused with psychiatric disorders. Thus representing a diagnostic problem for neurophyschiatrists. Here we review the grey zone between psychiatry and epilepsy on three levels. The first level is the semiology itself, that the behavioral phenomenon at a time can be the presentation of an epileptic disorder and at another time a representation of a psychiatric disorder. The second level is the comorbidity between epilepsy and psychiatric disorders namely epileptic psychosis. The third level is the disorders of the brain that can present by both epileptic and/or psychiatric disorders. We reviewed the current literature in both epilepsy and Psychiatry including the main presentations that might be confusing.
\end{abstract}

Conclusion:Epilepsy, schizophrenia like psychosis, intellectual disability, autism are different disorders that may share same semiological presentation, comorbidity or even etiology. A stepwise mental approach and decision making is needed excluding seizure disorder first before diagnosing a psychiatric one.

Keywords: epilepsy, psychosis, schizophrenia, semiology, autoimmune encephalitis
Volume 8 Issue I - 2017

\author{
Ahmed Gaber \\ Department of Neuropsychiatry,Ain Shams University, Egypt
}

Correspondence: Ahmed Gaber, Prof. of Neuropsychiatry, Ain Shams University, Cairo, Egypt, Email gaberedu@gmail.com

Received: June II, 2017 | Published: July 12, 2017

\section{Discussion}

Epilepsy is a brain disorder characterized by an enduring predisposition of recurrent seizures. Seizure is a transient recurrent disturbance of behavior due to excessive or synchronous neuronal activity in the brain. ${ }^{1}$ The behavioral disturbance in seizure involves disruption of one of four spheres that represents the semiology (phenomenology) of seizures. These spheres are the sensorial sphere, consciousness sphere, autonomic sphere and the motor sphere. ${ }^{2}$ The behavioral disturbances in these four spheres may mimic psychiatric non epileptic phenomena in there semiology, that may lead to confusion in diagnosis whether the patient is epileptic or a psychiatric disorder. This mimicry occurs on three levels constituting a grey zone. The first level is the semiology itself, that the behavioral phenomenon at a time can be the presentation of an epileptic disorder and at another time a representation of a psychiatric disorder. The second level is the comorbidity between epilepsy and psychiatric disorders namely epileptic psychosis. The third level is the disorders of the brain that can present by both epileptic and/or psychiatric disorders e.g. NMDA encephalitis. Here we review these three levels of Semiological Bridge between psychiatry and epilepsy.

\section{Level I: seizure semiology vs psychiatric semiology}

Seizures are not always objective, only the motor seizures that can be viewed as objective phenomena. However it can be also confused with psychogenic non epileptic seizures. The other spheres of seizures are more subjective than being objective phenomena. Seizures affecting the sensorial sphere exclusively produce no objective signs other than an occasional altered behavior by the patient to an "unexpected" experience. We are aware of their occurrence only if the patient reported it. These seizures are identified as auras. Seizures that interfere primarily with consciousness are called dialeptic seizures. Seizures consisting primarily of autonomic symptoms are called either autonomic "seizures" when they are objectives or "auras when they are subjective. ${ }^{2}$

\section{Auras}

Auras are ictal manifestations having sensory, psychosensory, autonomic and experiential symptoms that represent the first subjective localizing symptom of seizure. ${ }^{3}$ In general they are brief (seconds to minutes) but they may be prolonged constituting an aura status for up to days (aura continua). In most instances there are no or few EEG correlates, due to the small surface area of cortical neurons activated and this makes a challenge to the diagnosis. ${ }^{2-5}$ Auras can be documented only objectively if they are developed into motor or dialeptic seizures otherwise they may resemble nonspecific or psychiatric symptoms. ${ }^{2,3}$ More over the aura content may relate to the patient psychological makeup. Stimulation of mesiobasal temporal structures produce aura consistent with the ongoing psychopathological process. ${ }^{6,7}$ Auras can be divided into the following:

Somatosensory auras: Somatosensory auras consist of abnormal somatosensory sensations "paresthesia" that are limited to a clearly defined somatosensory region of the body. ${ }^{2-30}$ They range from tingling, numbness, electric like sensation, sense of movement or stiffness whether unilateral or bilateral. ${ }^{8,9}$ These paresthesia are a common feature in anxiety states and depression with multiple somatic complains. The only clue for differentiation is the clinical semiology. The paroxysmal nature, the recurrence, the presence of a march and stereotyped attacks in the same somatotopic presentation is mostly epileptic. ${ }^{8-30}$ The non-episodic nature and absence of stereotypy is more towards a non-epileptic phenomenon.

Visual auras: They are either clearly predominant visual hallucinations or illusions occurring in isolation. If they are associated with other complex distortions of perception (as altered sense of familiarity or hearing, complex visual or auditory illusions) it is considered psychic aura. ${ }^{2-30}$ Again the episodic transient nature and stereotypy of the visual phenomena is towards epileptic seizure. In contrast to psychotic hallucinations, they are time locked to the attack unless they are other forms of epileptic psychosis that will be described later on.

Auditory auras: Isolated auditory hallucinations or illusions should be classified as auditory auras. More elaborated auditory hallucinations 
or illusions that occur together with complex alterations of perception are classified as psychic auras..$^{2-30}$ This is mostly mistaken with schizophrenia.

Olfactory auras: is the perception of a smell is rare psychiatric phenomena and mostly epileptic in nature. ${ }^{12-30}$

Gustatory auras: is the perception of a taste as an epileptic phenomenon is classified as a gustatory aura. ${ }^{2}$

Abdominal auras: Patients with temporal lobe epilepsy frequently have auras with abdominal sensations. It may be accompanied by autonomic, emotional or sensory phenomena. ${ }^{15,30}$ The most common sensation is the rising epigastric sensation that is common in anxiety and panic attacks. ${ }^{15}$

Psychic auras: Psychic auras are multisensorial hallucinations that constitute an "experience"e.g. fear that someone is behind him. ${ }^{2,19}$ Emotional aura is an ictal fear with pronounced anxiety or intense terror that is out of proportion to, and separable from, the understandable apprehension that can accompany any seizure. In some patients, the fear resembles a real-life and sometimes is confused with panic attacks. It is accompanied by symptoms and signs of autonomic activation, such as mydriasis, tachycardia, and hyperventilation, and behavioral manifestations of screaming, calling for help, and agitated movements. ${ }^{16-18}$ The most typical example of psychic auras is distortions of familiarity, such as sensations of deja vu or jamais vu. ${ }^{20-22}$ They may present by forced thinking resembling intrusive thoughts of obsessive complex disorders, or forced acts resembling compulsions. ${ }^{8}$ Derealization or depersonalization can be the presenting symptom resembling dissociative fugue state. Amnestic seizure may last for hours to days that may be interpreted as psychogenic..$^{30}$ Living in a dreamy vivid state is an identified temporal lobe epileptic phenomenon that resembles psychosis. ${ }^{20-22}$ Autoscopy, a hallucination of self-image, is seeing oneself as a "double," or as an external entity observed from a distance after the mind is felt to have left the body. This can be confused with schizophrenia. ${ }^{23-30}$

Autonomic auras: Autonomic alterations elicited by epileptic activation of autonomic cortical centers produce symptoms that the patient can detect but that observers have difficulty identifying them. These include palpitations, hot flashes, piloerection, sweating, hyperventilation, blood pressure changes, cold, shivering and urinary urgency. ${ }^{25-29}$ If these phenomena could be monitored in epilepsy monitoring unit they became an autonomic seizure. ${ }^{2}$ Autonomic symptoms are a part of psychiatric complains in a lot of disorders. Here it is mandatory to determine the paroxysmal nature and stereotypy of the symptoms. The occurrence of these attacks during sleep is more towards epilepsy. The presence of EEG correlates in video EEG monitoring unit may be needed to diagnose the condition. The association of anxiety or panic like symptoms does not exclude epilepsy.

\section{Autonomic seizures}

Autonomic seizures consist of episodic alterations of autonomic function that are elicited by activation of autonomic cortical centers activated by an epileptiform dis- charge. ${ }^{2}$ The semiology of autonomic seizures is highly variable involving multiple systems..$^{30}$

a. Cardiovascular: Palpitations, arrhythmias, bradycardia, asystole, ictal syncope.

b. Gastrointestinal: Ictal vomiting, hypersalivation, spitting, diarrhea, fecal incontinence, hunger, borborygmi.

c. Genitourinary: Urinary urgency, erotic feeling, erection, orgasm. d. Respiratory: Apnea, hyperventilation, coughing, sighing, nocturnal laryngospasm.

e. Thermoregulatory: Fever.

f. Pupillary: Mydriasis, miosis.

These phenomena can occur separate or in association and they are often interpreted as psychogenic. However there recurrence, paroxysmal nature, stereotype, EEG correlates can diagnose the condition as epilepsy.

\section{Dialeptic seizures}

Dialeptic seizures are seizures in which the predominant symptomatology consists of an alteration of consciousness with unresponsiveness or decreased responsiveness. Usually associated with memory impairment for the event. ${ }^{2-30}$ Dialeptic seizures cannot be diagnosed as a psychiatric disorder, but when they present as a nonconvulsive status epilepticus they represent a diagnostic challenge. Non convulsive status epilepticus are prolonged non motor dialeptic, aura or autonomic status epilepticus. There are many subtypes as absence status epilepticus, obtundation status epilepticus, discognitive status epilepticus. All share a common main theme of presentation that they start abruptly with waxing and waning symptomatology lasting from hours to days, during which the patient is partially responsive and partially not with bizarre behavior, mood swings as if drunk with perceptual disturbances. ${ }^{31}$ The condition usually resemble acute psychotic episode and may be managed as a psychiatric disorder. A history of prior seizures, abnormal neurological examination, minor myoclonic jerks and an abnormal EEG suggest epileptic disorder. Also non convulsive status was reported to have as bizarre presentation as ictal catatonia. ${ }^{32}$

\section{Motor seizures}

Some motor seizures may appear bizarre enough to simulate psychogenic one.

a. Hypermotor seizures: They are complex movements involving the proximal segments of the limbs and trunk. This results in large movements that appear "violent" when they occur at high speeds. The "complex motor manifestations" imitate normal movements, but the movements are inappropriate for the situation and usually serve no purpose with preserved consciousness. They are usually diagnosed as histrionic behavior ${ }^{2-30}$.

b. Gelastic Seizures:Seizures in which the main motor manifestation is "laughing". They may be confused with incongruent affect. ${ }^{30}$

\section{Level II: epileptic psychosis}

A recent systematic review found that up to $6 \%$ of individuals with epilepsy have a comorbid psychotic illness and that patients have an almost eight fold increased risk of psychosis. The prevalence rate of psychosis is higher in temporal lobe epilepsy (7\%). ${ }^{33}$ Epileptic psychosis can be categorized into four types, chronic and acute interictal psychosis, post ictal psychosis and the fore mentioned ictal psychosis encountered in non-convulsive status epilepticus. Acute psychosis includes also the what is called alternative psychosis caused by forced normalization. ${ }^{34}$ Post ictal psychosis represents a rather homogenous clinical entity, while interictal psychosis is apparently quite heterogeneous. Most often, interictal psychosis is subdivided into chronic and acute interictal types, with the latter comprising also patients with alternative psychosis. ${ }^{35}$ Moreover, postictal and alternative psychoses can be seen as a large unified group of true epileptic psychosis, because both are closely associated with epileptic 
activity, even if the link is inversely related in cases of alternative psychosis. Meanwhile chronic interictal psychosis is consequently left as a remnant, which may be heavily dependent on genetic predisposition rather than epileptic activity with less association with temporal lobe epilepsy that is more near to schizophrenia rather than epilepsy. ${ }^{34-36}$ Epileptic psychoses are often overlooked, mistreated, and consequently lingering on needlessly. ${ }^{37}$ This is due to misdiagnosis as depression at the start with delay of administration of dopamineblockers. Moreover some antiepileptic drugs, such as vigabatrin, ${ }^{38}$ phenytoin, zonisamide, ${ }^{39}$ and topiramate, ${ }^{40}$ have been reported to show adverse psychotropic effect but this is still controversial. ${ }^{41}$ Interictal psychoses seem most troublesome to differentiate from a pure psychiatric illness. The presentation is quite similar to paranoid schizophrenia with perceptional abnormalities, with a mean latency of about 14.1years after onset of epilepsy although with a wide range. ${ }^{42}$ Clinically, factors that distinguish these patients from having pure schizophrenic illness were reported to include a typically better premorbid function, a preservation of affect, religious, moral, or ethical interests, ${ }^{43,44}$ absence of negative symptoms, formal thought disorder, and catatonia. ${ }^{45} \mathrm{~A}$ family history of psychosis, complex partial seizures or generalized tonic-clonic seizures, and borderline intellectual functioning are predictors for developing interictal psychosis. ${ }^{46}$ Psychiatric comorbidities are frequent in MTLE patients, and in population-based studies, epilepsy has been consistently associated with increased risk of schizophrenia. ${ }^{47}$ However, the exact biological substrate behind the association of MTLE and psychiatric comorbidities is unknown. ${ }^{48,49}$ A proven neuropathological alterations in the hippocampus of patients with epilepsy and the history of major depression or interictal psychosis, which may underlie psychiatric symptoms in MTLE. ${ }^{50-52}$ Also hippocampal neuroinflammatory related molecules show a distinct pattern of expression when MTLE patients present with a comorbid psychiatric diagnosis of interictal psychosis or major depression. ${ }^{53,54}$ Studies have reported successful treatment of patients with seizures, schizophrenia, and major depression using drugs with anti-inflammatory effect as an add-on therapy. ${ }^{5-58}$ Frontal epileptic seizures were also reported to present as epileptic psychosis. In a patient with a history of bipolar disorder, new psychotic features appeared as recurrent and stereotyped episodes of ictal psychosis with complex visual hallucinations associated with intense fear and disgust, secondary to frontal epileptic seizures. This highlights the challenge of diagnosing the epileptic nature of a new psychotic phenomenon in patients with previous psychiatric disorders. ${ }^{59}$

\section{Level III: neurological disorders presented by both epileptic and psychiatric presentations}

Several neurological disorders can have a shared psychiatric and epileptic presentation with confusion in the diagnosis till the full blown clinical picture appears. These can be autoimmune encephalitis, Hashimoto encephalopathy, or genetic disorders. ${ }^{60}$

\section{Autoimmune encephalitis}

Autoimmune limbic encephalitis was thought to be a paraneoplastic disorder especially small-cell lung cancer ${ }^{61}$ until 2001 when, a form of immunotherapy-responsive limbic encephalitis with IgG antibodies initially considered against voltage gated potassium channels (VGKC) was described. ${ }^{62,63}$ In 2005, Anti-N-Methyl-D-Aspartate receptor (antiNMDAR) encephalitis, an autoimmune disease with antibodies against the NR1/NR2B heteromer of the N-MethylD-Aspartate receptor, was identified and its relation to ovarian teratoma. ${ }^{64-67}$ It is characterized by acute mental status change, seizures, autonomic instability, hyperkinesia and presence of teratoma ${ }^{66-67}$ In quick succession, further neuronal cell surface antigens were characterized in patient cohorts with autoimmune encephalitis. They included the aamino3-hydroxy-5-methyl-4-isoxazol-propionic acid receptor (AMPAreceptor), ${ }^{68} \gamma$-aminobutyric acid (GABA)(b)-receptor, ${ }^{69} \alpha 1$-glycine receptor (GlyR), ${ }^{70}$ metabotropic glutamate receptor 5 (mGluR5), ${ }^{71}$ leucine-rich, glioma-inactivated 1 (LGI1), ${ }^{72,73}$ contactin-associated protein-like 2 (CASPR2), ${ }^{73,74}$ dopamine receptor 2 (D2-receptor) ${ }^{75}$ and dipeptidylpeptidase-like protein-6 (DPPX, a regulatory subunit of the KV4.2 potassium channel). ${ }^{76}$ Antibody-associated encephalitis can be subdivided into those in which the antibodies are directed against neuronal surface or intracellular antigens. ${ }^{77}$ Those with antibodies against neuronal surface antigens share a core syndrome of limbic encephalitis (epileptic seizures, short-term memory deficits, behavioral and psychiatric disturbances) with additional features that vary according to the immune response. ${ }^{78}$ Antibodies that occur without symptoms of limbic encephalitis include, mGluR1 (cerebellar symptoms), ${ }^{7}$ GlyR (spectrum of stiff-person syndrome, encephalomyelitis with rigidity) ${ }^{79}$ and dopamine-receptor D2 (basal ganglia encephalitis).$^{75}$ In this autoimmune encephalitis, anti-NMDAreceptor encephalitis is the most common and represents a diagnostic challenge. ${ }^{77}$ It starts by prodromal symptoms of fever, headache, nausea, vomiting and upper gastrointestinal symptoms ${ }^{80-87}$ In adults, this is followed a few days or weeks later by psychiatric symptoms and behavioral abnormalities (>95\%) often overshadowing other symptoms such as memory deficits (60-80\%). Affective, psychotic and obsessive compulsive syndromes can occur. Seizures and status epilepticus are common (70 \%); they are often the initial symptoms in children $(>30 \%) .{ }^{77}$ Involuntary movements are common orofacial dyskinesia, dystonia, oculogyric crisis (70-90 \%) (80-83). these symptoms are usually accompanied by progressive loss of consciousness $(60-70 \%)$ and autonomic instability $(50 \%) .{ }^{81}$ About $13 \%$ of patients develop partial forms of the syndrome characterized by predominant psychiatric disturbances, refractory seizures, status epilepticus, or movement disorders. In most of these cases a thorough neurological and neuropsychological examination reveals other features of the syndrome. Truly monosymptomatic manifestations are rare $(1 \%) .^{81}$

\section{Hashimoto's encephalopathy}

Hashimoto's encephalopathy (HE) is a rare, life-threatening, condition associated with elevated levels of anti-thyroid antibodies (anti-thyroid peroxidase and anti-thyroglobulin). Thyroid function is not predictive of clinical symptoms and outcome. It has a variable clinical presentation that includes: tremor, myoclonic jerks, ataxia, stroke-like episodes, neuropsychiatric symptoms (psychosis, behavioral changes, and cognitive impairment), seizures, impairment of consciousness and non-convulsive status. Since symptoms are variable and non-specific, the diagnosis is complex and requires both the exclusion of other causes of encephalopathy, psychiatric disorders, epilepsy and the demonstration of positive anti-thyroid antibody titer. ${ }^{84}$

\section{Genetic correlation between epilepsy and psychiatric disorders}

There is a growing body of evidence suggesting a shared genetic susceptibility between many neuropsychiatric disorders, including schizophrenia, autism, intellectual disability and epilepsy. The sodium channel, voltage-gated type II alpha subunit gene SCN2A has been shown to exhibit loss-of-function mutations in individuals with seizure disorders, intellectual disability, autism and schizophrenia. ${ }^{85-90}$ The leucine-rich glioma inactivated (LGI) genes associated with partial 
epilepsy with auditory features might also represent genes of interest for schizophrenia, especially among patients with prominent auditory hallucinations and formal thought disorder. ${ }^{60}$ Neurodevelopmental disorders such as attention deficit hyperactivity disorder and autism have a genetic susceptibility. These include deletions in the chromosome 21 , subtelomeric deletions, duplications and a maternally inherited duplication of the chromosomal region 15q11-q13; microdeletions in on the long (q) arm of the chromosome in a region designated q21; interstitial duplications encompassing 16p13.11. ${ }^{91}$ Micro deletions in q21 increases the risk of delayed development, intellectual disability, physical abnormalities, and neurological and psychiatric problems associated with autism, schizophrenia, and epilepsy and weak muscle tone (hypotonia). ${ }^{91}$ Deletions of the $15 \mathrm{q} 26$ region encompassing the chromodomain helicase DNA binding domain 2 (CHD2) gene have been associated with intellectual disability, behavioral problems, and several types of epilepsy. Absence epilepsy in an adolescent male with moderate intellectual disability, short-lasting psychoses, and an interstitial deletion in 15q26.1-q26.2 (CHD2) gene has been reported as well. ${ }^{92}$ Patients with the $15 \mathrm{q} 11.2 \mathrm{BP} 1-\mathrm{BP} 2$ microdeletion can present with developmental and language delay, neurobehavioral disturbances and psychiatric problems. Autism, seizures, schizophrenia and mild dysmorphic features are less commonly seen. ${ }^{33}$ These are only examples of shared genetics and comorbid epilepsy and psychiatric disorders.

\section{Conclusion}

Epilepsy, schizophrenia like psychosis, intellectual disability, and autism is different disorders that may share same semiological presentation, comorbidity or even etiology. This may present a diagnostic challenge. In such conditions the first thing is to exclude epilepsy. Clinically, any behavioral phenomena that fulfill the definition of an epileptic seizure are a seizure. That is any sudden, repetitive, stereotyped, paroxysmal behavioral phenomenon that is probably due to excessive cerebral neuronal discharge is a seizure. This is true for discrete seizures but cannot be applied to nonconvulsive status epilepticus. An abrupt onset of confusion, bizarre behavior, waxing and waning attention, and mini myoclonic jerks may be helpful. In most instances EEG is needed to confirm the diagnosis. The awareness of psychiatrist of this grey zone between epilepsy and psychiatry helps in not misdiagnosing these conditions.

\section{Acknowledgments}

None.

\section{Conflicts of interest}

Author declares there are no conflicts of interest.

\section{Funding}

None.

\section{References}

1. Fisher RS, Van Emde Boas W, Blume W, et al. Epileptic seizures and epilepsy: definitions proposed by the International League Against Epilepsy (ILAE) and the International Bureau for Epilepsy (IBE) Epilepsia. 2005;46(4):470-472.

2. Luders H, Acharya J, Baumgartner C, et al. Semiological seizure classification. Epilepsia. 1998;39(9):1006-1013.

3. Blume WT, Luders HO, Mizrahi E, et al. Glossary of descriptive terminology for ictal semiology: report of the ILAE task force on classification and terminology. Epilepsia. 2001; 42(9):1212-1218.
4. Luders H, Acharya J, Baumgartner C, et al. A new epileptic seizure classification based exclusively on ictal semiology. Acta Neurol Scand. 1999;99(3):137-141.

5. Wieser HG, Hailemariam $\mathrm{S}$, Regard M, et al. Unilateral limbic epileptic status activity: stereo EEG, behavioraL and cognitive data. Epilepsia. 1985;26(1):19-29.

6. Ferguson SM, Rayport M. Psychosis in epilepsy. In: Blumer D (ED.), Psychiatric Aspects of Epilepsy. American Psychiatric Press, Washington, USA. 1984. P.229-270.

7. Halgren E, Walter RD, Cherlow D, et al. Mental phenomena evoked by electrical stimulation of the human hippocampal formation and amygdala. Brain. 1978;101(1):83-117.

8. Penfield W, Jasper H. Epilepsy and the Functional Anatomy of the Human Brain. Brain. 1954;77(4):639-641.

9. Salanov V, Andermann F, Rasmussen T, et al. Parietal lobe epilepsy. Clinical manifestations and outcome in 82 patients treated surgically between 1929 and 1988. Brain. 1995;118(3):607-627.

10. Salanova V. Andermann F, Oliver A Rasmussen T, et al. Occipital lobe epilepsy: electroclinical manifestations, electrocorticography. Cortical stimulation and outcome in 42 patients treated between 1930 and 1991. Brain. 1992;115(6):1655-1680.

11. Ludwig BI, Ajmone-Marsan C. Clinical ictal patterns in epileptic patients with occipital electroencephalographic foci. Neurology. 1975;25(5):463-471.

12. Acharya V, Acharya J, Luders H. Olfactory epileptic auras. Neurology. 1998;51(1):56-61

13. Howe JG, Gbson JD. Uncinate seizures and tumors, a myth reexamined. Ann Neurol. 1982; 12(2):227.

14. Fried 1, Spencer DD, Spencer SS. The anatomy of epileptic auras: focal pathology and surgical outcome. J Neurosurg. 1995;83(1):60-66.

15. Van Buren JM. The abdominal aura: a study of abdominal sensations occurring in epilepsy produced by depth stimulation. Electroencephalogr Clin Neurophysiol. 1963;15:1-19.

16. Macrae D, Isolated fear. A temporal lobe aura. Neurology. 1954;4:479-505.

17. Mullan S, Penfield W. Illusions of comparative interpretation and emotion. AMA Arch Neurol Psychiatry. 1959;81(3):269-284.

18. Lanteaume L, Khalfa S, Régis J, et al. Emotion induction after direct intracerebral stimulations of human amygdala. Cereb Cortex. 2007;17(6):1307-1313.

19. Gloor P, Olivier A, Quesney LF, et al. The role of the limbic system in experiential phenomena of temporal lobe epilepsy. Ann Neurol. 1982;12(2):129-144.

20. Bancaud J, Brunet-Bourgin F, Chauvel P, et al. Anatomical origin of déjà vu and vivid 'memories' in human temporal lobe epilepsy. Brain. 1994;117(1):71-90.

21. Bartolomei F, Barbeau E, Gavaret M, et al. Cortical stimulation study of the role of rhinal cortex in déjà vu and reminiscence of memories. Neurology. 2004;63(5):858-864.

22. Taylor DC, Lochery M. Temporal lobe epilepsy: origin and significance of simple and complex auras. J Neurol Neurosurg Psychiatry. 1987; 50(6):673-681.

23. Devinsky O, Feldmann E, Burrowes K, et al. Autoscopic phenomena with seizures. Arch Neurol. 1989;46(8):1080-1088.

24. Maillard L, Vignal JP, Anxionnat R, et al. Semiologic value of ictal autoscopy. Epilepsia. 2004;45(4):391-394. 
25. Isnard J, Guénot M, Sindou M, et al. Clinical manifestations of insular lobe seizures: a stereo-electroencephalographic study. Epilepsia. 2004;45(9):1079-1090.

26. Green JB. Pilomotor seizures. Neurology. 1984;34(6):837-839.

27. Stefan H, Pauli E, Kerling F, et al. Autonomic auras: left hemispheric predominance of epileptic generators of cold shivers and goose bumps? . Epilepsia. 2002;43(1):41-45.

28. Loddenkemper T, Kellinghaus C, Gandjour J, et al. Localizing and lateralising value of ictal piloerection. J Neurol Neurosurg Psychiatry. 2004;75(6):879-883.

29. Loddenkemper T, Foldvary N, Raja S, et al. Ictal urinary urge: further evidence for lateralization to the nondominant hemisphere. Epilepsia. 2003;44(1):124-126.

30. Tufenkjian K, Lüders HO. Seizure Semiology: Its value and limitations in localizing the epileptogenic zone. J Clin Neurol. 2012;8(4):243-250.

31. Baykan B. Non convulsive status epilepticus: An intriguing, highly heterogeneous neuropsychiatric condition with blurring clinical margins, sharpening EEG criteria and still unsolved background. Noro Psikiyatr Ars. 2016;53(3):192-193.

32. Gaete $\mathrm{G}$ and Velásquez Á. Ictal catatonia presentation as a non-convulsive status epilepticus: A case report. Rev Med Chil. 2017;145(1):126-130.

33. Clancy MJ, Clarke MC, Connor DJ, et al. The prevalence of psychosis in epilepsy; a systematic review and meta-analysis. BMC Psychiatry. $2014 ; 14: 75$

34. Kousuke Kanemoto, Yukari Tadokoro, Tomohiro Oshima Psychotic illness in patients with epilepsy. Ther Adv Neurol Disord. 2012;5(6):321-334.

35. Trimble M. The Psychoses of Epilepsy. Raven Press, New York, USA 1991.

36. Sachdev P. Schizophrenia-like psychosis and epilepsy: the status of association. Am J Psychiatry. 1998;155(3):325-336.

37. Cornaggia C, Mascarini A. and Gobbi G. Severe psychiatric disorder in an 8-year-old boy with myoclonic-astatic seizures. In: Schmidt D and Schachter S (Eds.), 110 Puzzling Cases of Epilepsy. (2nd edn), Martin Dunitz, London. 2002. p.152-156.

38. Weber P, Dill P, Datta A. Vigabatrin induced forced normalization and psychosis - Prolongated termination of behavioral symptoms but persistent antiepileptic effect after withdrawal. Epilepsy Behav. 2012;24(1):138-140.

39. Noguchi T, Fukatsu N, Kato H, et al. Impact of antiepileptic drugs on genesis of psychosis. Epilepsy Behav. 2012;23(4):462-465.

40. Khan A, Faught E, Gilliam F, et al. Acute psychotic symptoms induced by topiramate. Seizure. 1999;8(4):235-237.

41. Mula M, Trimble M. The importance of being seizure free: topiramate and psychopathology in epilepsy. Epilepsy Behav. 2003;4(4):430-434.

42. Beletsky V, Mirsattari SM. Epilepsy, Mental Health Disorder, or Both? Epilepsy Research and Treatment Article ID 163731, 13. 2012

43. Bear D, Levin K, Blumer S, et al. Interictal behaviour in hospitalised temporal lobe epileptics: relationship to idiopathic psychiatric syndromes. J Neurol Neurosurg Psychiatry. 1982;45(6):481-488.

44. Perez MM, Trimble MR. Epileptic psychosis- Diagnostic comparison with process schizophrenia. Br J Psychiatry . 1980;137:245-249.

45. Perez MM, Trimble MR, Murray NMF, et al. Epileptic psychosis: an evaluation of PSE profiles. Br J Psychiatry. 1985;146:155-163.

46. Adachi N, Matsuura M, Okubo Y, et al. Predictive variables of interictal psychosis in epilepsy. Neurology. 2000;55(9):1310-1314.
47. Qin P, Xu H, Laursen TM, et al. Risk for schizophrenia and schizophrenialike psychosis among patients with epilepsy: population based cohort study. BMJ . 2005;331(7507):23.

48. Kandratavicius L, Lopes-Aguiar C, Bueno-Junior LS, et al. Psychiatric comorbidities in temporal lobe epilepsy: possible relationships between psychotic disorders and involvement of limbic circuits. Rev Bras Psiquiatr. 2012;34(4):454-66.

49. Kandratavicius L, Ruggiero RN, Hallak JE, et al. Pathophysiology of mood disorders in temporal lobe epilepsy. Rev Bras Psiquiatr. 2012;34 Suppl 2:S233-245.

50. Kandratavicius L, Hallak JE, Young LT, et al. Differential aberrant sprouting in temporal lobe epilepsy with psychiatric co-morbidities. Psychiatry Res. 2012;195(3):144-150.

51. Kandratavicius L, Monteiro MR, Assirati JA, et al. Neurotrophins in mesial temporal lobe epilepsy with and without psychiatric comorbidities. J Neuropathol Exp Neurol. 2013;72(11):102910-102942.

52. Kandratavicius L, Monteiro MR, Hallak JE, et al. Microtubuleassociated proteins in mesial temporal lobe epilepsy with and without psychiatric comorbidities and their relation with granular cell layer dispersion. Biomed Res Int. 2013;2013:960126.

53. Kandratavicius L, Peixoto-Santos JE, Monteiro MR, et al. Mesial temporal lobe epilepsy with psychiatric comorbidities: a place for differential neuroinflammatory interplay. Journal of Neuroinflammation. 2015;12:38.

54. Kandratavicius L, Hallak JE, Carlotti CG, et al. Hippocampal expression of heat shock proteins in mesial temporal lobe epilepsy with psychiatric comorbidities and their relation to seizure outcome. Epilepsia. 2014;55(11):1834-1843

55. Krogias C, Hoepner R, Muller A, et al. Successful treatment of anti-Caspr2 syndrome by interleukin 6 receptor blockade through tocilizumab. JAMA Neurol. 2013;70(8):1056-1059.

56. Chaudhry IB, Hallak J, Husain N, et al. Minocycline benefits negative symptoms in early schizophrenia: a randomised double-blind placebo-controlled clinical trial in patients on standard treatment. $J$ Psychopharmacol. 2012;26(9):1185-1193

57. Muller N, Schwarz MJ, Dehning S, et al. The cyclooxygenase-2 inhibitor celecoxib has therapeutic effects in major depression: results of a double-blind, randomized, placebo controlled, add-on pilot study to reboxetine. Mol Psychiatry. 2006;11(7):680-684.

58. Devinsky O, Vezzani A, Najjar S, et al. Glia and epilepsy: excitability and inflammation. Trends Neurosci. 2013;36(3):174-184.

59. Manfiolia V, Saladinia M, Cagnin A. Ictal visual hallucinations due to frontal lobe epilepsy in a patient with bipolar disorder. Epilepsy \& Behavior Case reports. 2013;1:146-149.

60. Cascella N G, Schretlen DJ, Sawa A. Schizophrenia and epilepsy: Is there a shared susceptibility?. Neurosci Res. 2009;63(4):227-235.

61. Corsellis JA, Goldberg GJ, Norton AR. "Limbic encephalitis" and its association with carcinoma. Brain. 1968;91:481-496.

62. Liguori R, Vincent A, Clover L, et al. Morvan's syndrome: periphera and central nervous system and cardiac involvement with antibodies to voltage-gated potassium channels. Brain. 2001;124(12):2417-2426.

63. Buckley C, Oger J, Clover L, et al. Potassium channel antibodies in two patients with reversible limbic encephalitis. Ann Neurol. 2001;50(1):73-78

64. Ances BM, Vitaliani R, Taylor RA, et al. Treatment-responsive limbic encephalitis identified by neuropil antibodies: MRI and PET correlates. Brain. 2005;128(8):1764-1777.

65. Dalmau J, Gleichman AJ, Hughes EG, et al. Anti-NMDA-receptor encephalitis: case series and analysis of the effects of antibodies. Lance Neurol. 2008;7(12):1091-1098. 
66. Dalmau J, Lancaster E, Martinez-Hernandez E, et al. Clinical experience and laboratory investigations in patients with anti-NMDAR encephalitis. Lancet Neurol. 2011;10(1):63-74.

67. Lee LH, Lu CJ. Long-term and Strong Immunotherapy to Treat AntiN-MethylD-Aspartate Receptor Encephalitis with Refractory Status Epilepticus. Acta Neurol Taiwan. 2016;25(3):99-103.

68. Lai M, Hughes EG, Peng X, et al. AMPA receptor antibodies in limbic encephalitis alter synaptic receptor location. Ann Neurol. 2009;65(4):424-434.

69. Lancaster E, Lai M, Peng X, et al. Antibodies to the GABAB receptor in limbic encephalitis with seizures: case series and characterization of the antigen. Lancet Neurol. 2010;9(1):67-76.

70. Hutchinson M, Waters P, McHugh J, et al. Progressive encephalomyelitis, rigidity, and myoclonus: a novel glycine receptor antibody. Neurology 2008;71(16):1291-1292.

71. Lancaster E, Martinez-Hernandez E, Titulaer MJ, et al. Antibodies to metabotropic glutamate receptor 5 in the Ophelia syndrome. Neurology . 2011;77(18):1698-1701.

72. Lai M, Huijbers MGM, Lancaster E, et al. Investigation of LGI1 as the antigen in limbic encephalitis previously attributed to potassium channels: a case series. Lancet Neurol. 2010;9(8):776-785.

73. Irani SR, Alexander S, Waters $\mathrm{P}$, et al. Antibodies to Kv1 potassium channel-complex proteins leucine-rich, glioma inactivated 1 protein and contactin-associated protein-2 in limbic encephalitis, Morvan's syndrome and acquired neuromyotonia. Brain. 2010;133(9):2734-2748.

74. Lancaster E, Huijbers MGM, Bar V, Boronat A, et al. Investigations of caspr2, an autoantigen of encephalitis and neuromyotonia. Ann Neurol. 2011;69(2):303-311.

75. Dale RC, Merheb V, Pillai S, et al. Antibodies to surface dopamine-2 receptor in autoimmune movement and psychiatric disorders. Brain. 2012;135(11):3453-3468.

76. Boronat A, Gelfand JM, Gresa-Arribas N, et al. Encephalitis and antibodies to dipeptidylpeptidase-like protein-6, a subunit of Kv4.2 potassium channels. Ann Neurol. 2013;73(1):120-128.

77. Leypoldt F, Wandinger K, Bien CG, et al. Autoimmune Encephalitis. Eur Neurol Rev. 2013;8(1):31-37.

78. Mas N, Saiz A, Leite MI, et al. Antiglycine-receptor encephalomyelitis with rigidity. J Neurol Neurosurg Psychiatry. 2011;82(12):1399-1401.

79. Marignier R, Chenevier F, Rogemond V, et al. Metabotropic glutamate receptor type 1 autoantibody-associated cerebellitis: a primary autoimmune disease?. Arch Neurol . 2010;67(5):627-630.

80. Dalmau J, Lancaster E, Martinez-Hernandez E, et al. Clinical experience and laboratory investigations in patients with anti-NMDAR encephalitis. Lancet Neurol . 2011;10(1):63-74.
81. Titulaer MJ, McCracken L, Gabilondo I, et al. Treatment and prognostic factors for long-term outcome in patients with anti-NMDA receptor encephalitis: an observational cohort study. Lancet Neurol. 2013;12(2):157-165.

82. Kleinig TJ, Thompson PD, Matar W, , et al. The distinctive movement disorder of ovarian teratomaassociated encephalitis. Mov Disord. 2008;23(9):1256-1261.

83. Hacohen $\mathrm{Y}$, Wright $\mathrm{S}$, Waters $\mathrm{P}$, et al. Paediatric autoimmune encephalopathies: clinical features, laboratory investigations and outcomes in patients with or without antibodies to known central nervous system autoantigens. $J$ Neurol Neurosurg Psychiatry. 2013;84(7):748-755.

84. Monti G, Pugnaghi M, Ariatti A, et al. Non-convulsive status epilepticus of frontal origin as the first manifestation of Hashimoto's encephalopathy. Epileptic Disord. 2011; 13 (3):253-258.

85. Sanders SJ, Murtha MT, Gupta AR, et al. De novo mutations revealed by whole-exome sequencing are strongly associated with autism. Nature. 2012;485(7397):237-241.

86. Fromer M, Pocklington AJ, Kavanagh DH, et al. De novo mutations in schizophrenia implicate synaptic networks. Nature. 2014;506(7487):179-184.

87. Rauch A, Wieczorek D, Graf E, et al. Range of genetic mutations associated with severe non-syndromic sporadic intellectual disability: an exome sequencing study. Lancet. 2012;380(9854):1674-1682.

88. Li J, Cai T, Jiang Y, et al. Genes with de novo mutations are shared by four neuropsychiatric disorders discovered from NPdenovo database. Mol Psychiatry. 2015;21(2):290-297.

89. Codina-Solà M, Rodríguez-Santiago B, Homs A, et al. Integrated analysis of whole-exome sequencing and transcriptome profiling in males with autism spectrum disorders. Mol Autism. 2015;6:21.

90. Carroll LS, Woolf R, Ibrahim Y, et al. Mutation screening of SCN2A in schizophrenia and identification of a novel loss-of-function mutation. Psychiatr Genet. 2016;26(2):60-65.

91. Badescu GM, Filfan M, Sandu RE, et al. Molecular mechanisms underlying neurodevelopmental disorders, ADHD and autism. Rom $J$ Morphol Embryol. 2016;57(2):361-366.

92. Verhoeven WM, Egger JI, Knegt AC, et al. Absence epilepsy and the CHD2 gene: an adolescent male with moderate intellectual disability, short-lasting psychoses, and an interstitial deletion in 15q26.1-q26.2. Neuropsychiatr Dis Treat. 2016;12:1135-1139.

93. Cox DM, Butler MG. The 15q11.2 BP1-BP2 Microdeletion Syndrome: A Review. Int J Mol Sci. 2015;16:4068-4082. 